\title{
Resilient emotionality and molecular compensation in mice lacking the oligodendrocyte-specific gene Cnp1
}

\author{
NM Edgarr ${ }^{1}$, C Touma ${ }^{2}$, R Palme $^{3}$ and E Sibille ${ }^{1}$
}

\begin{abstract}
Altered oligodendrocyte structure and function is implicated in major psychiatric illnesses, including low cell number and reduced oligodendrocyte-specific gene expression in major depressive disorder (MDD). These features are also observed in the unpredictable chronic mild stress (UCMS) rodent model of the illness, suggesting that they are consequential to environmental precipitants; however, whether oligodendrocyte changes contribute causally to low emotionality is unknown. Focusing on $2^{\prime}-3^{\prime}$-cyclic nucleotide $3^{\prime}$-phosphodiesterase (Cnp1), a crucial component of axoglial communication dysregulated in the amygdala of MDD subjects and UCMS-exposed mice, we show that altered oligodendrocyte integrity can have an unexpected functional role in affect regulation. Mice lacking Cnp1 (knockout, KO) displayed decreased anxiety- and depressive-like symptoms (i.e., low emotionality) compared with wild-type animals, a phenotypic difference that increased with age (3-9 months). This phenotype was accompanied by increased motor activity, but was evident before neurodegenerativeassociated motor coordination deficits ( $\leqslant 9-12$ months). Notably, $C_{n p} 1^{\mathrm{KO}}$ mice were less vulnerable to developing a depressivelike syndrome after either UCMS or chronic corticosterone exposure. Cnp $1^{\mathrm{KO}}$ mice also displayed reduced fear expression during extinction, despite normal amygdala c-Fos induction after acute stress, together implicating dysfunction of an amygdalarelated neural network, and consistent with proposed mechanisms for stress resiliency. However, the Cnp $1^{K O}$ behavioral phenotype was also accompanied by massive upregulation of oligodendrocyte- and immune-related genes in the basolateral amygdala, suggesting an attempt at functional compensation. Together, we demonstrate that the lack of oligodendrocytespecific Cnp1 leads to resilient emotionality. However, combined with substantial molecular changes and late-onset neurodegeneration, these results suggest the low Cnp1 seen in MDD may cause unsustainable and maladaptive molecular compensations contributing to the disease pathophysiology.
\end{abstract}

Translational Psychiatry (2011) 1, e42; doi:10.1038/tp.2011.40; published online 20 September 2011

\section{Introduction}

Disruptions in neuronal signaling long have been the focus of research on major depressive disorder (MDD). More recently, however, glial disruptions have been postulated to contribute to the pathophysiology of MDD, ${ }^{1-3}$ and the roles of specialized glial subtypes are now being investigated. Although alterations in microglia ${ }^{4-6}$ and astrocyte-related components ${ }^{7-10}$ are observed in MDD, oligodendrocyte alterations in MDD are becoming a primary focus of research. ${ }^{2}$ Oligodendrocytes, the main myelin-forming cells of the central nervous system, provide both structural and trophic support for neurons, and facilitate axonal conduction. In the amygdala and prefrontal cortex of MDD subjects, previously reported decreases in glial cell number were attributed to reduced oligodendrocyte number, ${ }^{11,12}$ consistent with patterns of downregulation of oligodendrocyte-related transcripts in amygdala ${ }^{13}$ and nearby temporal cortex. ${ }^{14}$ Changes in NG2 cells, a cell type sharing a common lineage with oligodendrocytes, ${ }^{15,16}$ have also been associated with depression-related characteristics in rodents. For instance, both chronic corticosterone exposure and chronic stress in rodents decreased cortical and limbic oligodendrocyte ${ }^{17}$ and NG2 cell proliferation. ${ }^{18,19}$ Rats given electroconvulsive seizure therapy, an antidepressant treatment for otherwise non-responsive MDD subjects, showed increased proliferation of NG2 cells in the amygdala and hippocampus. ${ }^{18,20,21}$ Thus, evidence suggests that oligodendrocytes, a crucial element for maintaining optimal neuronal function, may be vulnerable to stress-related insults and may contribute to the pathophysiology of MDD.

We previously identified a set of dysregulated gene transcripts in the amygdala of male subjects with familial MDD, including robust downregulations of multiple oligodendrocyte-related genes. ${ }^{13}$ This pattern was also observed in mice following unpredictable chronic mild stress (UCMS) ${ }^{22}$ and appeared restricted to the amygdala (not anterior cingulate cortex or dentate gyrus). $2^{\prime}-3^{\prime}$-Cyclic nucleotide $3^{\prime}$-phosphodiesterase (Cnp1) was one of several oligodendrocyte-specific genes significantly downregulated across species. In addition, Cnp1 was previously implicated in $\mathrm{MDD}^{14,23}$ and schizophrenia, ${ }^{24-26}$ supporting the hypothesis

\footnotetext{
${ }^{1}$ Department of Psychiatry, Translational Neuroscience Program and Center for Neuroscience, University of Pittsburgh, Pittsburgh, PA, USA; ${ }^{2}$ Research Group of Psychoneuroendocrinology, Max Planck Institute of Psychiatry, Munich, Germany and ${ }^{3}$ Department of Biomedical Sciences/Biochemistry, University of Veterinary Medicine, Vienna, Austria

Correspondence: Dr E Sibille, Department of Psychiatry, 3811 O'Hara Street, BST W1643, University of Pittsburgh, Pittsburgh, PA 15213, USA.

E-mail: sibilleel@upmc.edu
}

Keywords: Cnp; depression; myelin; oligodendrocyte; stress; UCMS

Received 12 May 2011; revised 29 July 2011; accepted 8 August 2011 
that altered Cnp1 function may participate in the pathophysiology of psychiatric disorders. Although Cnp1 is expressed at low levels in the periphery, it is expressed at higher levels in NG2 cells and it comprises $\sim 4 \%$ of myelin-associated proteins in mature oligodendrocytes. ${ }^{27} \mathrm{Cnp} 1$ is localized to non-compact myelin in the inner mesaxon and paranodal loops, ${ }^{28}$ the principle sites of contact with the axon. Cnp1 binds microtubules and regulates mRNA expression and transport at the paranode, ${ }^{29}$ although its exact role in axoglial communication is not known. The lack of Cnp1 protein in mice results in disorganization of nodal sodium channels and paranodal adhesion proteins (e.g., Caspr and Nav)..$^{30,31}$ Adult Cnp1 ${ }^{K O}$ mice do not initially show an overt behavioral phenotype, but develop progressive axonal degeneration and motor deficits after 6 months of age, leading to premature death. ${ }^{30,31}$

Healthy oligodendrocytes are necessary to maintain optimal axon function; ${ }^{32}$ however, it remains to be determined whether oligodendrocyte-specific alterations are causal to MDD, as opposed to compensatory or neutral side effects in psychiatric disorders. Here, we investigated the effect of a lack of Cnp1 on emotionality (i.e. anxiety and depressive-like behaviors) in mice, under baseline conditions (trait) and after chronic stress or corticosterone exposure, two validated paradigms for inducing high-emotionality states. To summarize the number of behavioral tests that were performed, and to obtain comprehensive and integrated measures in each group, emotionality- and locomotion-related data were normalized using a Z-score methodology previously described. ${ }^{33}$ As the amygdala is a central region in affect regulation and as our initial findings showed low Cnp1 in the amygdala of MDD patients, ${ }^{34}$ we also assessed amygdala function in $C n p 1^{K O}$ mice using fear conditioning (FC), c-Fos induction and gene expression profiling. The experiments show that lack of Cnp1 results in low emotionality under baseline and induced states, along with reduced corticolimbic fear expression, a suggested mechanism for stress resilience.

\section{Materials and methods}

Animals. $\mathrm{Cnp}^{\mathrm{KO}}$ mice were obtained from KA Nave and C. Lappe-Siefke (Max Planck Institute, Göttingen, Germany). Adult male and female $C n p 1^{K O}$ and wild-type (WT) littermate mice (C57BL/6 background) ${ }^{31}$ were obtained from heterozygous crossings and microchipped for identification. Five cohorts were used: Baseline Cohort $(N=11-17$ per group; 6 and 9 months baseline), UCMS Cohort $(N=8-12$ per group, 6 months of age), CORT Cohort ( $N=10-14$ per group; 3-month baseline and CORT exposure), FC Cohort $(N=16-19$ per group, 3 and 6 months of age) and cFos Cohort ( $N=6$ per group, 6 months of age). Mice were maintained under standard conditions (group housed, 12/12-hour light/dark cycle, $22 \pm 1{ }^{\circ} \mathrm{C}$, food and water ad libitum). All testing was conducted in compliance with the National Institutes of Health laboratory animal care guidelines and with protocols approved by the Institutional Animal Care and Use Committee.

Behavioral measures. Major depression is defined as a syndrome (i.e., collection of symptoms) including low mood or anhedonia, accompanied by cognitive (e.g., attention, concentration) and physiological symptoms (e.g., weight, locomotor and sleep pattern changes), and frequently comorbid with significant anxiety symptoms. Thus, the emotionality component is best characterized in mice by a comprehensive panel of behavioral tests for anxiety-like and depressive-like emotionality, and for antidepressant-like behavior. Hence, Baseline, UCMS and CORT Cohorts were tested in the elevated plus maze (EPM), open field (OF), novelty suppressed feeding (NSF), forced swim test (FST) and rotarod as described, ${ }^{35}$ and in the following order: EPM, OF, NSF, FST, rotarod, separated by a minimum of 1-2 days. Detailed methods are provided in the Supplementary Material.

Behavioral Z-scoring. To address behavioral variability and obtain comprehensive and integrated measures in each group, emotionality- and locomotion-related data were normalized using a Z-score methodology previously described. ${ }^{33}$ Briefly, for each behavioral measure, Z-scores for individual animals were calculated using the formula below, which indicates how many s.d.'s $(\sigma)$ an observation $(X)$ is above or below the mean of a control group $(\mu)$.

$$
z=\frac{X-\mu}{\sigma}
$$

$Z$-scores for behavioral measures were first averaged within test, and then across test to ensure equal weighting of the four tests comprising the final Z-score (Figure 1b). Separate $Z$-scores were calculated for the Baseline, UCMS and CORT Cohorts using the means and s.d.'s of the respective control groups (i.e., 'WT' for Baseline or 'WT control' for UCMS and CORT). Locomotion Z-scores were similarly obtained from EPM (total crosses) and OF (total distance traveled) data.

Estrous phase. Female mice in the UCMS and 3-month Baseline Cohorts were assessed for estrous phase on the day of behavioral testing after the EPM, OF and NSF tests to control for potential effects of hormonal fluctuations on behavior. Estrus, metestrus, diestrus and proestrus were determined via vaginal cytology ${ }^{36}$ as previously described. ${ }^{33}$

Unpredictable chronic mild stress. Single-housed mice were subjected to 4 weeks of a randomized schedule of 1-2 mild stressors per day, 7 days per week. Detailed methods are in the supplements and full table of stressors in Supplementary Table 1.

Chronic corticosterone treatment. As described previously, ${ }^{33}$ mice were given corticosterone $\left(35 \mu \mathrm{g} \mathrm{ml}^{-1}\right.$; Sigma-C2505, St Louis, MO, USA) dissolved in $20 \%$ cyclodextrin (Sigma $\mathrm{H} 107)$ as their only water supply for 4 weeks. Owing to the reduced cohort size, behavior of all mice was tested both before (3-month baseline) and following CORT exposure.

Fear conditioning. The protocol was performed over 3 days using a computer-controlled system (Coulbourn Instruments, Allentown, PA, USA) (Figure 3a). On day 1, mice were trained to associate a conditioned stimulus (CS; $80 \mathrm{db}, 2 \mathrm{kHz}, 15 \mathrm{~s}$ tone) to an unconditioned stimulus (US); $0.5 \mathrm{~mA}, 0.5 \mathrm{~s}$ footshock) in context A (shock floor, silver/ aluminum walls, $70 \%$ ethanol cleanser). On day 2 , mice 
a

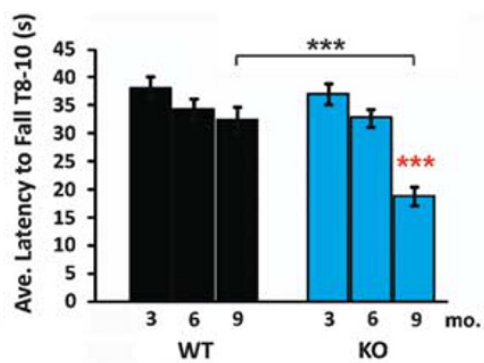

b
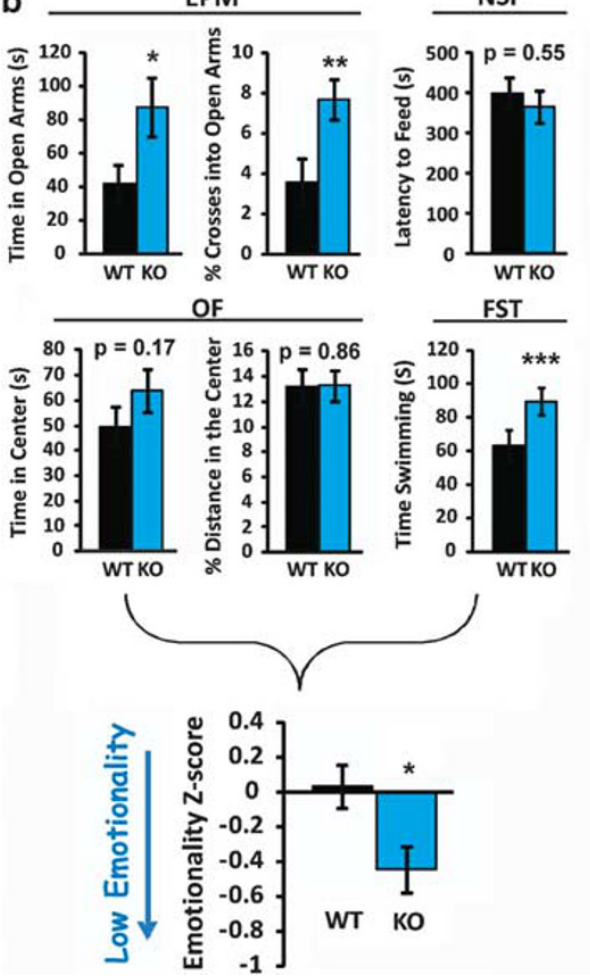

NSF

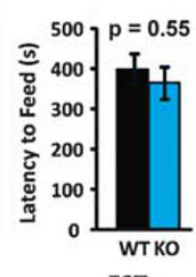

FST

c

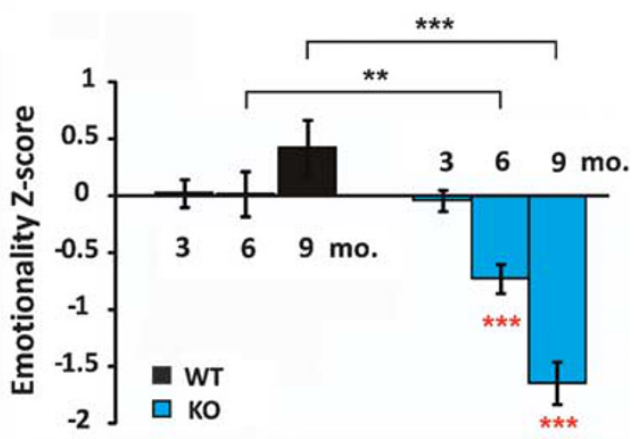

d

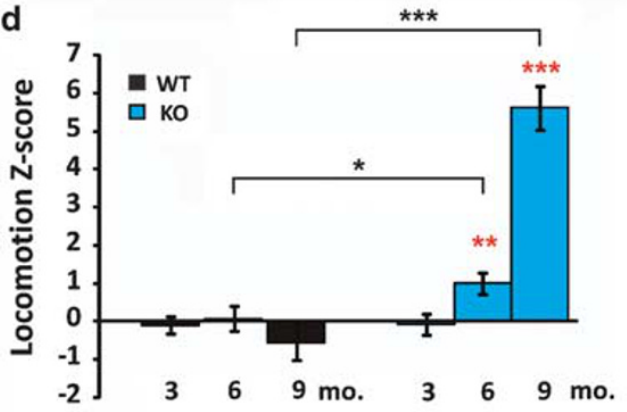

Figure $1 \mathrm{Cnp} 1^{K O}$ baseline behavior at 3, 6 and 9 months of age. (a) Latency to fall on the rotarod. Cnp $1^{K O}$ mice show significant motor coordination deficits at 9 months. (b) Example of individual behavioral measures combined in the emotionality Z-scores (6-month time-point). See also Materials and methods, and Guilloux et al. ${ }^{33}$ for Z-scoring methodology. $\mathrm{Cnp}^{\mathrm{KO}}$ mice showed significant changes in elevated plus maze (EPM) and forced swim test (FST), and nonsignificant changes in novelty suppressed feeding (NSF) and open field (OF). In NSF, no differences in weight loss or post-test food consumption were noted (data not shown). EPM, OF, NSF and FST measures were normalized using WT means and s.d.'s, and averaged per group. ${ }^{33}$ Breakdown of Z-scores for other age groups are presented in Supplementary Figures 1-3. (c) High emotionality Z-scores indicate elevated anxiety-related and depressive-like behaviors. (d) Similarly derived locomotion Z-scores indicate elevated locomotor activity. Z-scores are normalized to the 3-month WT group for both emotionality and locomotion. Red asterisks represent within-genotype age comparisons. Black asterisks represent across genotype comparisons. Data represent mean \pm s.e.m. ( $N=9-18$ per group). ${ }^{\star} P<0.05,{ }^{\star \star} P<0.01,{ }^{\star \star *} P<0.001$.

received 30 trials of the CS only in context $B$ (non-shock grid floor, black walls, Windex cleanser). On day 3 , mice were placed back in context $B$ (extinction recall) followed by context A (fear renewal) $1 \mathrm{~h}$ later; and freezing was recorded during five CS exposures in each context. On each day, a 2-min acclimation period preceded and followed testing. Trials were presented with a variable inter-trial interval (25$35 \mathrm{~s}$ ) and percent freezing was measured during the 15-s CS.

Immunohistochemistry. Stress-induced c-Fos immunoreactivity was performed as described. ${ }^{37}$ Brains were collected by perfusion at $120 \mathrm{~min}$ following a 15-min restraint stress. Sections $(40 \mu \mathrm{m}$, six per mouse) were incubated with c-Fos antibody (polyclonal rabbit anti-c-Fos; 1:5000 dilution; Calbiochem, San Diego, CA, USA), followed by secondary biotinylated goat-anti-rabbit lgG (1:500 dilution; Vector Laboratories, Burlingame, CA, USA), and visualized with diaminobenzidine solution (DAB Peroxidase Substrate Kit; Vector Laboratories). Total numbers of c-Fos-positive cells were counted in the basolateral amygdala (BLA).

Gene array. Brains from the UCMS Cohort $(N=11-13$ mice per group) were selected, based on emotionality Z-scores that were closest to the means of their group. Following dissection, brains were immediately flash frozen on dry ice. As the other hemisphere was allotted for other experiments, the left BLA was dissected directly on the cryostat using a $0.5-\mathrm{mm}$ micropunch, tissue samples were frozen at $-80^{\circ} \mathrm{C}$ until extraction and total RNA was extracted using an RNeasy Mini Kit (Qiagen, Germantown, MD, USA). 
Concentration and purity were tested using a Bioanalyzer and Nanodrop Spectrophotometer $(260 / 280 \geqslant 1.8)$. One half of each RNA sample $(\sim 150 \mathrm{ng})$ was processed on Illumina Mouse WG-6v2 Expression BeadChips (San Diego, CA, USA) at the Keck Microarray facility (Yale University, New Haven, CT, USA) and expression levels were determined using the Illumina BeadArray Reader. The other half was used for independent verification by real-time quantitative PCR. Two internal controls verified the validity of the arrays (see Results): (1) Cnp1 is downregulated/absent in Cnp1 ${ }^{K O}$ and (2) Cnp1 is downregulated in WT mice following UCMS. ${ }^{22}$

Real-time quantitative PCR. Total RNA was converted into cDNA using the qScript cDNA synthesis kit (Quanta Biosciences, Gaithersburg, MD, USA). As previously described, real-time quantitative polymerase chain reaction reactions were assessed by SYBR green fluorescence signal (Invitrogen, Carlsbad, CA, USA) using the Opticon Monitor DNA Engine (Bio-Rad, Berkeley, CA, USA). ${ }^{13}$ Briefly, samples were run in quadruplicates and $\Delta \mathrm{C}_{t}$ values were determined by comparison with the geometric mean of three reference genes (housekeeping genes: actin, GAPDH and cyclophilin). Signal intensities $\left(\mathrm{SI}=100 \times 2^{-\Delta \mathrm{C}(\mathrm{t})}\right)$ were used for comparison with microarray expression values.

Statistical analysis. There were no significant effects of sex or estrous phase in all examined cohorts, hence, male and female groups were combined, where appropriate. Genotype differences in Baseline and CORT Cohorts were assessed using repeated measures analysis of variance (ANOVA) for age and treatment, respectively. Genotype comparisons with the 3-month Baseline group were made using one-way ANOVA. The UCMS Z-scores were assessed using a two-way ANOVA for genotype and treatment. Weekly measures in UCMS (fur rating, body weight and corticosterone levels) were assessed using two-way repeated measures ANOVA for week, with genotype and treatment as cofactors. Genotype differences in the FC Cohort were assessed using repeated measures analysis of covariance with age as a covariate for days 1 (conditioning) and 2 (extinction) and one-way analysis of covariance for day 3 (recall and renewal). Genotype differences in the c-Fos Cohort were determined using two-way ANOVA for genotype and stress. Gene expression changes across genotype were assessed in four subgroups: WT-Control, WT-UCMS, KO-Control and KO-UCMS, using ANOVA followed by twogroup post hoc tests for gene selection (Supplementary Table 2). Selection criteria were set at $P<0.01$ and effect size greater than $30 \%$. Genotype differences in real-time quantitative PCR were assessed with one-way ANOVA.

\section{Results}

$C n p 1^{K O}$ mice display low baseline/trait emotionality and high locomotor activity. Consistent with prior reports, Cnp1 $1^{K O}$ mice showed normal motor coordination in the rotarod test at 3 and 6 months of age, and showed deficits in mice aged 9 months (Figure 1a). Mice were grossly impaired at 12 months of age and could not perform the rotarod test (data not shown). Therefore, we tested the impact of reduced Cnp1 on emotionality in male and female mice at 3, 6 and 9 months of age (i.e., before and during mild neurodegenerative-related stages), using four behavioral paradigms (EPM, OF, NSF and FST). To extract stable patterns underlying behavioral variability and summarize results across tests, emotionality-related measures were normalized to the 3-month WT group, and averaged per mouse across tests to obtain integrated 'emotionality Z-scores'33 (See Materials and methods, and example of 6-month time-point in Figure 1b). $C n p 1^{K O}$ mice were comparable to WT mice at 3 months of age and displayed progressively decreasing emotionality Z-scores at 6 and 9 months of age (Figure 1c and Supplementary Figures 1-3). It is unlikely that changes were due to repeated testing (at 6 and 9 months) as a pattern of decreased emotionality in WT mice would be expected, although $C n p 1^{K O}$-specific memory-related events cannot be ruled out (See Fear conditioning tests). Although EPM and OF emotionality measures were controlled for locomotor activity, FST results could reflect differences in activity. Removing the FST from the emotionality Z-score decreased power, but the same progressive pattern of low emotionality was observed in Cnp $1^{K O}$ mice $(6$ months $P=0.07 ; 9$ months $P<0.0004$; Supplementary Figure 4).

Integrated Z-score measures of locomotor activity revealed a concomitant progressive increase from 3 to 9 months of age in $C n p 1^{K O}$ mice (Figure 1d and Supplementary Figures 1-3). Cnp $1^{K O}$ mice also displayed lower body weight at 6 and 9 months compared with WT, but had normal levels of stress hormones (Supplementary Figures $5 \mathrm{a}$ and b). Together, these results are supportive of a time-dependent decrease in emotionality in $C n p 1^{K O}$ mice, which is paralleled by a progressive elevated locomotor phenotype.

Cnp1 ${ }^{\text {KO }}$ mice are resistant to developing high emotionality states in two distinct rodent models of depression. To test whether low baseline emotionality also conferred reduced vulnerability to develop high emotionality states, we exposed two independent cohorts of $C n p 1^{K O}$ mice to environmental (UCMS) or neuroendocrine (CORT) stressors for a period of 4 weeks. In both experiments, WT groups responded with robust and characteristic increases in emotionality (Figures $2 \mathrm{a}$ and b). $C n p 1^{K O}$ mice responded with increased emotionality after UCMS compared with nonstressed $\mathrm{Cnp1}^{\mathrm{KO}}$ mice (Figure 2a; Supplementary Figure 6), but displayed a trend toward lower emotionality following CORT exposure (Figure 2b; Supplementary Figure 7). Notably, following both paradigms, $\mathrm{Cnp} 1^{K O}$ mice remained at emotionality levels that were lower than WT non-stressed groups (Figures $2 a$ and $b$ ). These differences remained when FST was excluded from Z-score analyses (Supplementary Figures $8 \mathrm{a}$ and b) and were confirmed in an independent cohort (Supplementary Figure 9). Note that the UCMS Cohort was 6 months of age at testing, hence, the low emotionality and high locomotion of $\mathrm{Cnp}^{K O}$ mice match prior results (Figure 1), thus, independently confirming the Baseline phenotype.

UCMS increased locomotion in WT (trend level) but not in Cnp $1^{K O}$ mice (Figure 2c; Supplementary Figure 6). CORT exposure reduced locomotion in WT and increased locomotion in $\mathrm{Cnp1}^{\mathrm{KO}}$ mice (Figure 2d; Supplementary Figure 7). 
a
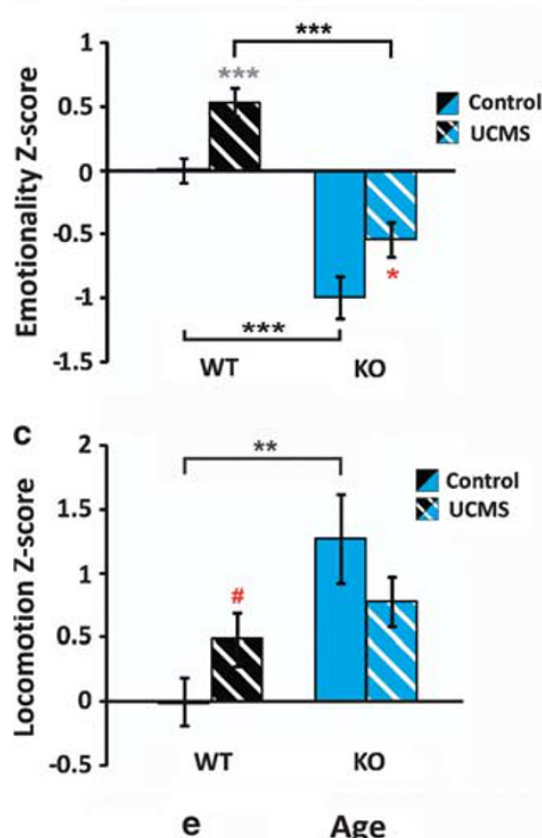

b CORT Cohort (3 months)
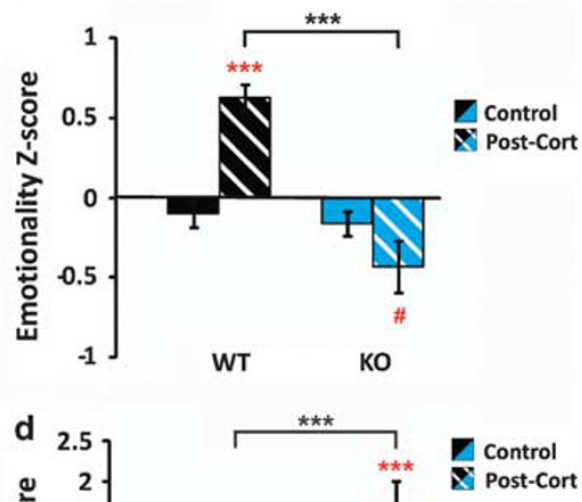
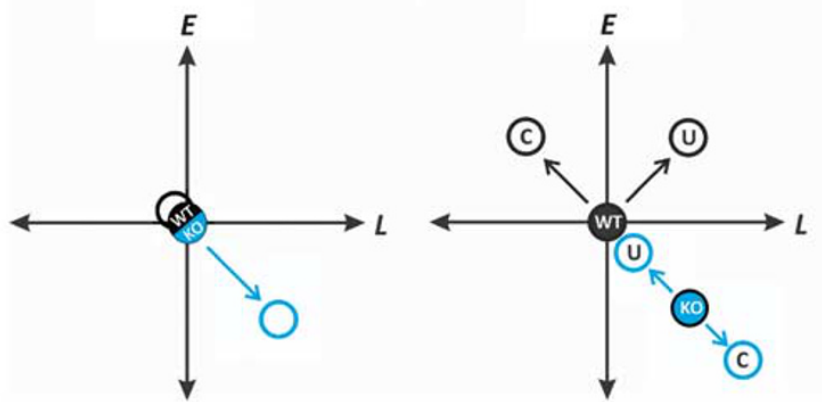

Figure 2 Effects of two rodent models of depression in $\mathrm{Cnp}^{\mathrm{KO}}$ mice. Emotionality Z-scores in the unpredictable chronic mild stress (UCMS) (a) and chronic corticosterone treatment (CORT) (b) Cohorts. Locomotion Z-scores in the UCMS (c) and CORT (d) Cohorts. Z-scores were normalized to wild-type (WT) control groups within each experimental cohort. Differences in $\mathrm{Cnp}^{\mathrm{KO}}$ control groups between the cohorts reflect age differences (UCMS, 6 months; CORT, 3 months). Schematic diagrams of emotionality and locomotion interactions in WT and $\mathrm{Cnp}^{\mathrm{KO}}$ mice across age (e) and after UCMS or CORT exposure. (f) WT mice showed dissociation in emotionality/ locomotion effects between the two depression models, whereas changes in $\mathrm{Cnp}^{K O}$ remained along the same axis. Red asterisks represent within genotype age comparisons. Black asterisks represent across genotype comparisons. Data represent mean \pm s.e.m. $\left(N=10-14\right.$ per group). ${ }^{*} P<0.05,{ }^{\star \star} P<0.01,{ }^{\star \star \star} P<0.001$ and \# represent statistical trends $(P<0.1)$.

No notable genotype differences were seen in weight gain, fur rating or in corticosterone levels in either paradigm (Supplementary Figures $10 \mathrm{a}-\mathrm{c}$ and $11 \mathrm{a}-\mathrm{c}$ ). In summary, $C n p 1^{K O}$ mice displayed reduced vulnerability to develop high emotionality behaviors after chronic environmental and neuroendocrine challenges, as emotionality Z-scores never reached WT levels. Notably, dissociations between changes in emotionality and locomotor activity were observed between genotype groups (Figures $2 \mathrm{e}$ and $\mathrm{f}$ ).

Normal fear conditioning and cellular reactivity to stress, but reduced fear expression, suggest low encoding of emotional salience in $\mathrm{Cnp1}^{\mathrm{KO}}$ mice. Our motivating study indicated reduced Cnp1 levels in the amygdala of MDD subjects and UCMS-exposed mice. To test whether the observed behavioral phenotype included disrupted amygdala function, we assessed $\mathrm{Cnp}^{\mathrm{KO}}$ mice in the FC paradigm (Figure 3a), a test relying on amygdala processing. Similar to WT, $C n p 1^{K O}$ mice learned to associate the CS with the US on day 1 (Figure $3 b$; left panel). On day 2 , both groups showed intact extinction learning, but $\mathrm{Cnp} 1^{\mathrm{KO}}$ mice displayed lower CS-induced freezing from the onset, resulting in significantly lower freezing throughout the extinction paradigm (Figure $3 b$; right panel), an indication of low fear expression. ${ }^{38}$ No significant differences in pain sensitivity were observed in the hot plate test (Supplementary Figure 12). These results were confirmed in a separate cohort $(N=8-12$ per genotype; $P<0.01$ for extinction; Supplementary Figure 13). This robust genotype difference was consistently observed during extinction recall and fear renewal (day 3 ), and was not due to lack of consolidation of fear memory (Supplementary Figure 14).

To assess whether the observed differences could reflect baseline changes in stress-induced activation of 
a

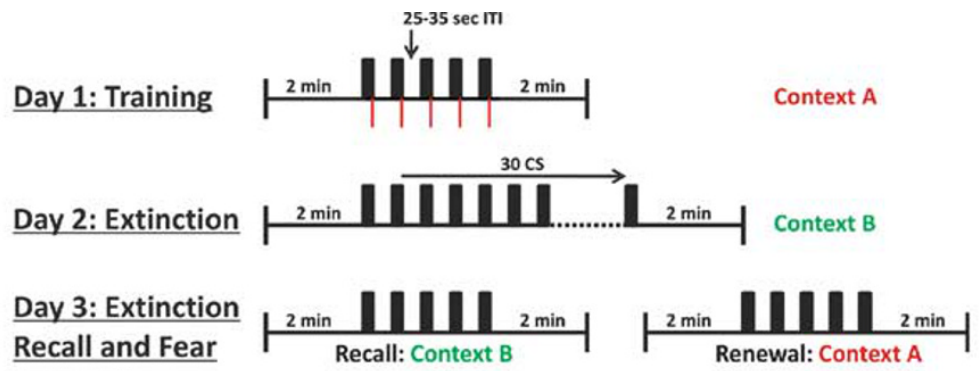

Renewal

CS: $80 \mathrm{db}, 2 \mathrm{kHz}, 15 \mathrm{sec}$ Tone $\quad$ US: $0.5 \mathrm{~mA}, 0.5 \mathrm{sec}$ footshock

b

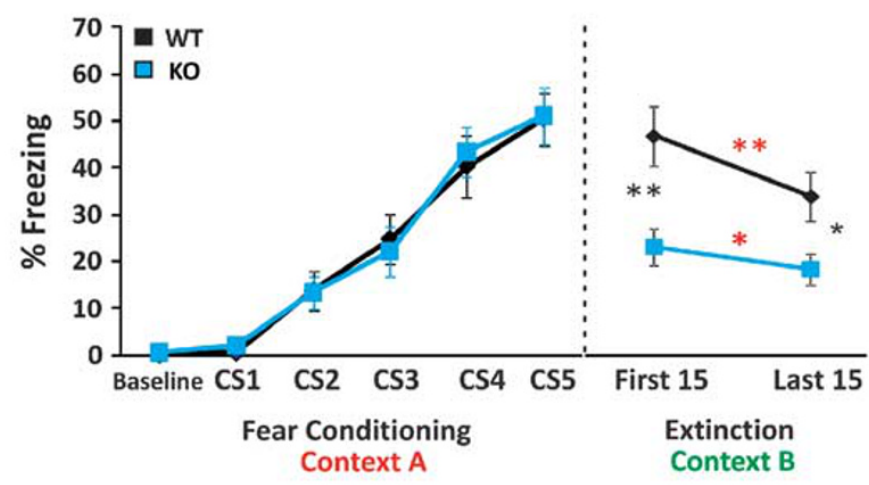

C

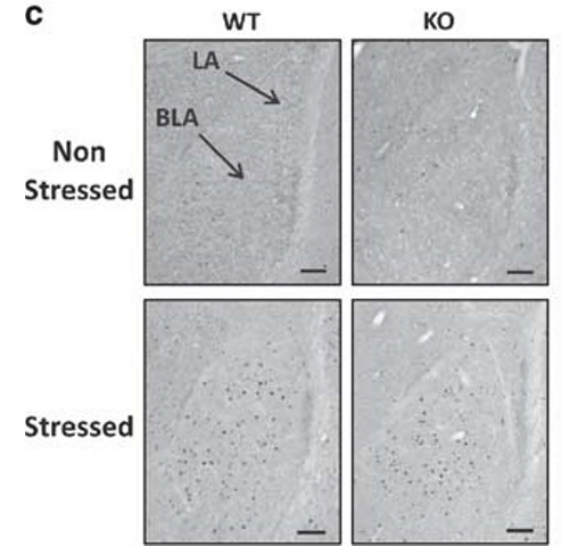

ко

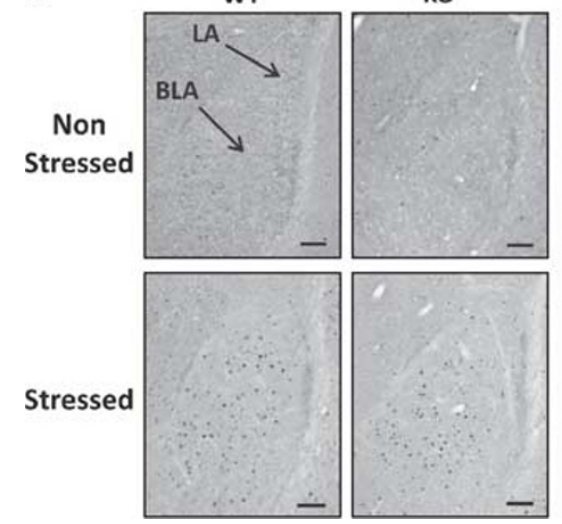

d

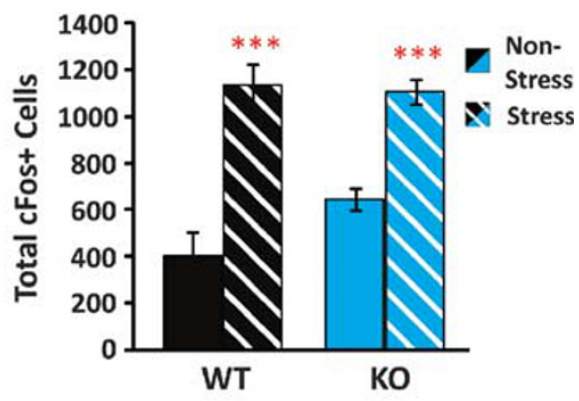

Figure 3 Fear conditioning (FC) and c-Fos analysis. (a) FC protocol. (b) Percent freezing during FC and extinction. (c,d) Analysis of stress-induced cFos expression in basolateral amygdala (BLA) of wild-type (WT) and Cnp1 ${ }^{K O}$ mice. (c) c-Fos expression in the amygdala under $10 \times$ magnification, scale bar $=0.1 \mathrm{~mm}$. (d) Total c-Fos-positive cell counts. Although there was a trend $(P<0.1)$ toward a genotype difference in the non-stressed groups, no significant differences were found between WT and Cnp1 ${ }^{K O}$. In all the panels, red asterisks represent within-genotype comparisons. Black asterisks represent across-genotype comparisons. Data represent mean \pm s.e.m. ( $N=16-19$ per group and $N=9-18$ per group). ${ }^{\star} P<0.05,{ }^{\star \star} P<0.01,{ }^{\star \star *} P<0.001$.

the amygdala, we measured the expression of the immediate early gene c-Fos in the BLA of a separate cohort of animals following a 15 -min restraint stress. WT and Cnp $1^{K O}$ mice displayed similar baseline (although at trend level for increased reactivity in $\mathrm{Cnp}^{K O}$ mice) and similar stressinduced number of c-Fos-positive cells (Figures $3 c$ and d), indicating intact BLA response to acute stress in $\mathrm{Cnp} 1^{\mathrm{KO}}$ mice.

\section{Upregulated oligodendrocyte- and immune-related gene} transcripts in the BLA of $\mathrm{Cnp1}^{K O}$ mice. To investigate putative underlying amygdala-related mechanisms, large-scale gene expression was assessed by microarray in the BLA of
WT and $C n p 1^{K O}$ mice from the UCMS Cohort (Figure 4a). Internal verification of the array data confirmed that Cnp1 levels were undetectable in $C n p 1^{K O}$ mice (Figure 4b) and downregulated in UCMS-exposed WT mice for two out of three probes (Figure 4c). ${ }^{13,22}$ UCMS-exposed Cnp $1^{K O}$ (KOUCMS) mice showed a similar pattern of transcript changes as UCMS-exposed WT mice $(R=0.72$; Supplementary Figure 15), indicating that the broad biological response to stress is intact. However, owing to the phenotypic differences, these UCMS-related genes are unlikely to be related to the behavioral phenotype in $C n p 1^{K O}$ mice. Instead, on the basis of consistent low emotionality in control and UCMS-exposed $\mathrm{Cnp}^{\mathrm{KO}}$ mice, we focused on genes 
displaying similar changes under control and UCMS conditions, as potential 'mediators' of the behavioral phenotype. In total, 114 ' $\mathrm{Cnp} 1^{\mathrm{KO}}$-associated probesets' were identified by the following criteria: (1) significant difference in $\mathrm{Cnp}^{K O}$ under control (KO-Control vs WTControl) and UCMS-exposed (KO-UCMS vs WT-UCMS) conditions $(P<0.01$; effect size $>30 \%)$, (2) consistent directionality of effect in both groups and (3) no change in WT after UCMS $(P>0.1)$.

On the basis of prior identification of relative glial/neuronal enrichment of transcript origin, ${ }^{39} 97 \%$ of the 114 identified transcripts were enriched in glial or mixed glial/neuronal origin. Specifically, a systematic upregulation of oligodendrocyte-related transcripts was observed $\left(24 \%\right.$ of $C n p 1^{K O}$. associated genes), including genes involved in structure, function and production of the myelin sheath (Table 1). In parallel, we observed a significant upregulation of immune-related transcripts $\left(32 \%\right.$ of $\mathrm{Cnp}^{\mathrm{KO}}$-associated genes), including genes associated with the immune complement system and major histocompatibility complex (Table 1; see also Supplementary Table 2). Ingenuity pathway analysis of $C n p 1^{K O}$-associated genes identified a gene network linking oligodendrocyte with immune genes, suggesting that the upregulation of immune-related genes may be synchronized with the dysregulation of oligodendrocyte-related genes in $C n p 1^{K O}$ mice. Only two neuronal-enriched genes were identified (Cortistatin and Serpina3n), suggesting minimal structural and/or functional adjustment in neurons.

\section{Discussion}

Focusing on an oligodendrocyte gene (Cnp1) that is critical for neuronal support and that is dysregulated in MDD, we tested

a
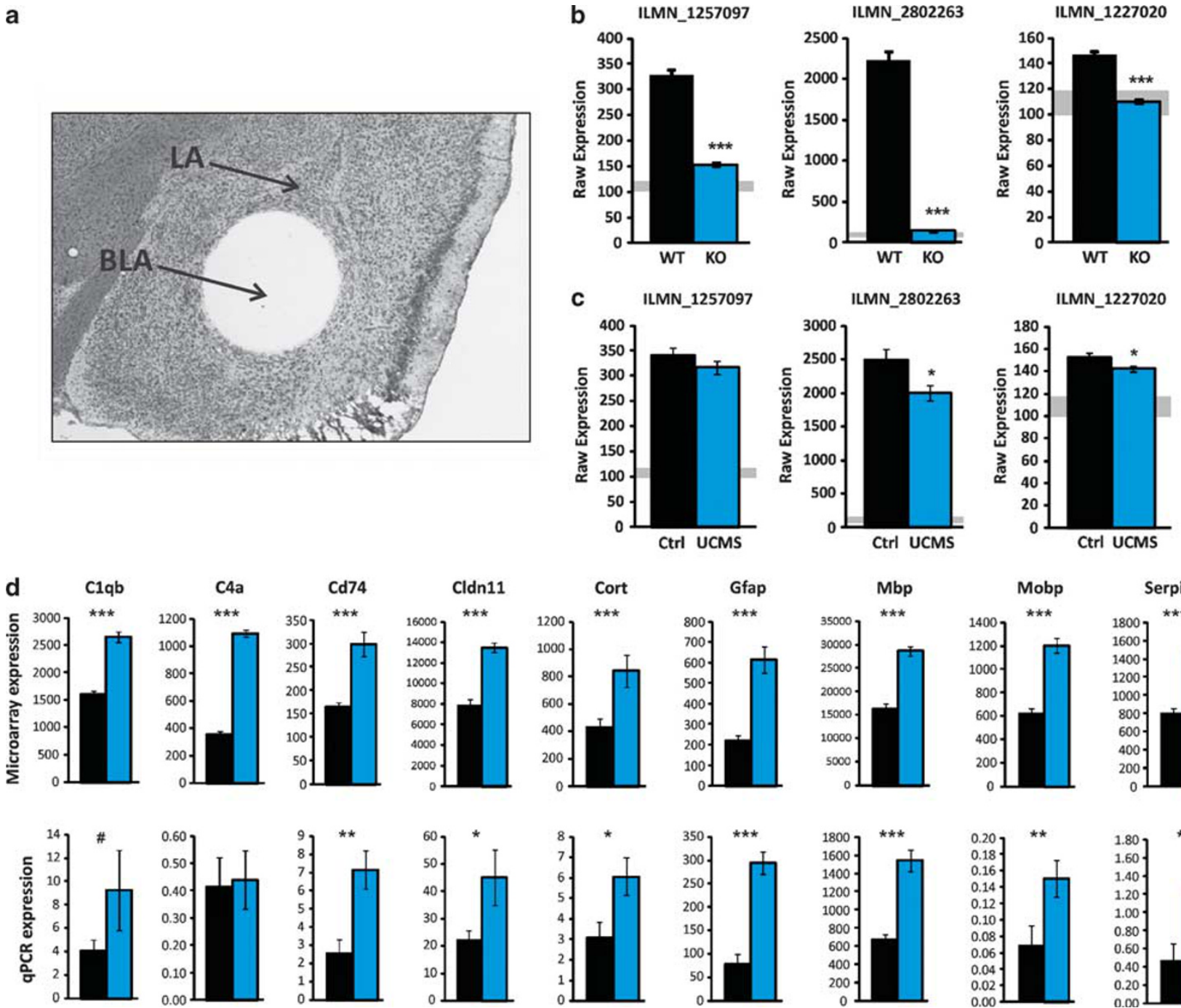

Figure 4 Basolateral amygdala (BLA) gene array analysis and real-time quantitative PCR validation (a) BLA tissue micropunch. (b) Absence of expression of the three Cnp1 probes in $\mathrm{Cnp}^{\mathrm{KO}}$ mice. Expression levels were at the threshold of detection ( $\sim 100-120 \mathrm{U}$; gray shading). (c) Downregulation of two out of three Cnp1 probes in wildtype (WT) mice exposed to unpredictable chronic mild stress (UCMS). (d) Real-time quantitative PCR confirms significant upregulation of eight out of nine genes. Data represent mean \pm s.e.m. (Microarray $N=11-13$ per group; real-time quantitative $P C R N=6$ per group). ${ }^{*} P<0.05,{ }^{* *} P<0.01,{ }^{* *} P<0.001$ and \# represent statistical trends $(P<0.1)$. 
Table 1 Selection of significantly affected neuronal, oligodendrocyte and immune-related genes between Cnp1 ${ }^{K O}$ and WT control mice

\begin{tabular}{|c|c|c|c|}
\hline \multirow{2}{*}{\begin{tabular}{|l} 
Gene Symbol \\
Serpina3n
\end{tabular}} & \multirow{2}{*}{$\begin{array}{ll}\text { Gene Title } \\
\text { serine (or cysteine) peptidase inhibitor clade A member 3N (Serpina3n) }\end{array}$} & \multicolumn{2}{|c|}{$\begin{array}{l}\text { alr p value } \\
(K O \text { vs. WT) }\end{array}$} \\
\hline & & 0.81 & $2.13 \mathrm{E}-10$ \\
\hline Cort (2) & cortistatin & 0.73 & 5.14E-06 \\
\hline Mag & myelin-associated glycoprotein & 1.16 & $6.64 \mathrm{E}-18$ \\
\hline Tspan2 & tetraspanin 2 & 0.95 & $1.51 \mathrm{E}-16$ \\
\hline Tmem10 & transmembrane protein 10 & 1.10 & $6.76 \mathrm{E}-16$ \\
\hline Cldn11 & claudin 11 & 0.98 & $2.59 \mathrm{E}-15$ \\
\hline Adamts4 & a disintegrin-like and metallopeptidase (reprolysin type) with thrombospondin type 1 motif, 4 & 0.73 & 2.66E-15 \\
\hline Mbp & myelin basic protein transcript variant 7 & 0.83 & $3.68 \mathrm{E}-15$ \\
\hline Tmem125 & transmembrane protein 125 & 0.80 & $9.05 \mathrm{E}-14$ \\
\hline Mal & myelin and lymphocyte protein T-cell differentiation protein & 0.83 & $1.48 \mathrm{E}-13$ \\
\hline Slc44a1 & solute carrier family 44 member 1 & 0.73 & $3.90 \mathrm{E}-13$ \\
\hline PIIp & plasma membrane proteolipid & 0.67 & 1.34E-12 \\
\hline Plp1 & proteolipid protein (myelin) 1 & 0.48 & 2.99E-12 \\
\hline Gltp & glycolipid transfer protein & 0.56 & $1.80 \mathrm{E}-11$ \\
\hline Mcam & melanoma cell adhesion molecule & 0.64 & 2.66E-11 \\
\hline Gjc2 & gap junction protein gamma 2 (Gjc2) transcript variant 2 & 0.69 & 4.09E-11 \\
\hline Fgfr2 & fibroblast growth factor receptor 2 transcript variant 2 & 0.48 & $5.44 \mathrm{E}-11$ \\
\hline $\mathrm{Cd} 9$ & CD9 antigen & 0.75 & $9.35 \mathrm{E}-11$ \\
\hline Rhog & ras homolog gene family member G & 0.63 & $1.62 \mathrm{E}-10$ \\
\hline Elovl1 & elongation of very long chain fatty acids-like 1 transcript variant 2 & 0.46 & 5.27E-10 \\
\hline Mobp (4) & myelin-associated oligodendrocytic basic protein & 0.95 & 8.59E-09 \\
\hline Ddr1 & discoidin domain receptor family member 1 transcript variant 1 & 0.50 & 1.09E-07 \\
\hline Fa2h & fatty acid 2-hydroxylase & 0.44 & 5.64E-07 \\
\hline Pmp22 & peripheral myelin protein & 0.42 & 8.64E-07 \\
\hline $\operatorname{Mog}(2)$ & myelin oligodendrocyte glycoprotein & 0.77 & 9.17E-07 \\
\hline Nkx6-2 & NK6 transcription factor related locus 2 (Drosophila) & 0.45 & $1.14 \mathrm{E}-05$ \\
\hline Lyz (2) & lysozyme & 1.78 & 8.29E-21 \\
\hline Ly86 & lymphocyte antigen 86 & 0.77 & 3.06E-20 \\
\hline$\underline{\mathrm{Cd} 52}$ & CD52 antigen & 1.39 & 4.74E-20 \\
\hline Fcer1g & Fc receptor, IgE, high affinity I, gamma polypeptide & 0.74 & $5.96 \mathrm{E}-18$ \\
\hline $\mathrm{C} 4 \mathrm{a}(2)$ & complement component 4A (Rodgers blood group) & 1.50 & $4.58 \mathrm{E}-16$ \\
\hline Tyrobp & TYRO protein tyrosine kinase binding protein & 0.73 & $5.52 E-16$ \\
\hline Cd63 & CD63 antigen & 0.59 & $7.72 \mathrm{E}-16$ \\
\hline Cyba & cytochrome b-245 alpha polypeptide & 0.65 & $1.49 \mathrm{E}-15$ \\
\hline C1qa & complement component 1 q subcomponent alpha polypeptide & 0.70 & 2.67E-15 \\
\hline C1qb & complement component 1 q subcomponent beta polypeptide & 0.76 & 2.89E-15 \\
\hline Trem2 & triggering receptor expressed on myeloid cells 2 & 0.70 & 8.75E-15 \\
\hline$\underline{\mathrm{C}} \mathbf{4 b}$ & complement component 4B (Childo blood group) & 1.24 & $9.36 \mathrm{E}-15$ \\
\hline$\underline{\text { C1qc }}$ & complement component 1 q subcomponent $\mathrm{C}$ chain & 0.69 & 3.47E-14 \\
\hline Fcgr3 & Fc receptor IgG low affinity III & 0.50 & 3.35E-13 \\
\hline Lgals3 & lectin galactose binding soluble 3 & 0.74 & $5.33 \mathrm{E}-13$ \\
\hline Ctsc & cathepsin C & 0.54 & 7.47E-13 \\
\hline Osmr & oncostatin M receptor & 0.45 & 2.12E-12 \\
\hline Hven1 & hydrogen voltage-gated channel 1 transcript variant 1 & 0.41 & 2.77E-12 \\
\hline $\mathrm{B} 2 \mathrm{~m}(2)$ & beta-2 microglobulin & 0.56 & $7.65 \mathrm{E}-12$ \\
\hline KIhl6 & kelch-like 6 (Drosophila) & 0.40 & $3.93 \mathrm{E}-10$ \\
\hline Litaf & LPS-induced TN factor & 0.54 & $6.06 \mathrm{E}-10$ \\
\hline Ndrg1 & $\mathrm{N}$-myc downstream regulated gene 1 & 0.56 & 8.96E-10 \\
\hline Lyz2 & lysozyme 2 & 0.73 & 1.39E-09 \\
\hline Cd68 & CD68 antigen & 0.56 & $1.98 \mathrm{E}-09$ \\
\hline Lag3 & lymphocyte-activation gene 3 & 0.68 & 2.27E-09 \\
\hline Cd82 & CD82 antigen & 0.55 & 4.69E-09 \\
\hline Adssl1 & adenylosuccinate synthetase like 1 & 0.48 & 7.37E-08 \\
\hline Cd74 (2) & CD74 antigen (major histocompatibility complex class II antigen-associated) transcript variant 2 & 0.66 & 1.33E-06 \\
\hline
\end{tabular}

Abbreviations: Alr, average log ratio $\left(\mathrm{Cnp}^{\mathrm{KO}} / \mathrm{WT}\right)$; KO, knockout; WT, wild type.

Number of redundant probes is shown following the gene symbol. Red, neuronal-enriched genes; blue, oligodendrocyte-enriched genes; underline, immune-related genes. The listed $P$-values represent the main genotype effect from the ANOVA analysis (see Supplementary Table 2 ).

the potential mechanistic link between altered oligodendrocyte function and emotionality in mice. We show that removal of Cnp1 in mice leads to unexpected reduced baseline emotionality, reduced fear expression (during extinction) and lower vulnerability to develop high emotionality states using two rodent paradigms to induce depressive-like states.
This behavioral profile suggests the presence of a dysfucntional amygdala-related network that is consistent with proposed mechanisms for stress resiliency. Gene array analysis in the BLA of $C n p 1^{K O}$ mice revealed a robust upregulation of oligodendrocyte- and immune-related transcripts, potentially representing functional compensations. 
Cnp $1^{K O}$ mice show a low baseline emotionality phenotype (trait) that appears progressively over time, but that is observed before the onset of motor coordination deficits (9-12 months), indicating that it is not due to the late-onset widespread axonal degeneration observed in $\mathrm{Cnp} 1^{K O}$ mice. ${ }^{31}$ Rather, more discrete molecular changes in myelin structure have been observed at earlier ages, which may contribute to the observed phenotype. For instance, the direct functional consequence of Cnp1 ablation is not known, but disorganization of critical proteins (e.g., Caspr, Nav) at the paranode region at 3 months and degeneration in some small diameter axons as early as post-natal day 15 were reported in $C n p 1^{K O}$ mice. ${ }^{30,40}$ Hence, impaired paranode function may translate into suboptimal support for neuronal axons, hence priming the system for dysregulated physiological responses to stress/fear.

Cnp $1^{K O}$ mice also display a concomitant increase in locomotor activity. Tests of emotionality control for activity, but locomotor and emotionality phenotypes are often difficult to dissociate in rodent models. In fact, quantitative trait loci mapping studies have identified regions on chromosomes 2, 7 and 8 that encode for both anxiety-related behavior and locomotion in rats, ${ }^{41}$ and the well-characterized high emotionality and low locomotion phenotypes of mice ${ }^{42}$ or rats ${ }^{43}$ lacking the serotonin transporter associate with common genetic loci. ${ }^{43}$ Hence, instead of a confounding factor, altered locomotor activity may represent an epistatic outcome of genetic disruptions of emotionality regulators, which are nevertheless dissociable under certain genetic and/or stress-induced conditions (Figures $2 \mathrm{e}$ and $\mathrm{f}$ ).

Cnp $1^{K O}$ mice have normal amygdala cellular reactivity (c-Fos measures) and fear acquisition, but display low fear expression during extinction learning (Figure 3), which was not likely due to poor consolidation of the fear memory (Supplementary Figure 14). Instead, we speculate that reduced fear expression in $\mathrm{Cnp}^{\mathrm{KO}}$ mice may result from low encoding of emotionality salient stimuli (e.g., the original fear association). Accordingly, Cnp1 ${ }^{K O}$ mice respond to chronic behavioral (UCMS) or physiological (CORT) stress (Figure 2a), but their induced emotionality states remained significantly below the levels associated with depressive-like states in WT mice (Figures $2 \mathrm{a}$ and $\mathrm{b}$ ). Together, this behavioral pattern is consistent with stress resilient phenotype. Indeed, in humans, resilience is associated with the ability to adapt to chronic stress $^{44}$ and to perceive stressful events in a less threatening way, ${ }^{45-47}$ both characteristics observed here in $\mathrm{Cnp} 1^{K O}$ mice. Fear expression is dependent on BLA function, ${ }^{48,49}$ but is also modulated by regions of the prefrontal cortex. ${ }^{38,50}$ Similarly, in humans, the ventromedial prefrontal cortex modulates amygdala function during fear extinction ${ }^{51}$, and potent ventromedial prefrontal cortex inhibition of the amygdala is postulated to occur in resilient individuals. ${ }^{44,52}$ Together, this suggests the presence of a dysfunctional amygdala-related neural network in $C n p 1^{K O}$ mice, consistent with proposed mechanisms for stress resilience. As disruption in related networks including prefrontal and/or hippocampal regions cannot be excluded, future site-specific and time-dependent alterations could further refine the role of Cnp1.

Microarray evaluation of transcript levels within the BLA of $C n p 1^{K O}$ mice indicated a robust pattern of upregulated oligodendrocyte-related transcripts. This suggests an attempted compensation for the lack of structure/function due to missing Cnp1, and potentially reflects prior reports of enlargement of the myelin inner tongue in small diameter axons and whirls of excess redundant myelin sheaths seen early in $\mathrm{Cnp1}{ }^{\mathrm{KO}}$ mice. ${ }^{30}$ Microarray assessment also revealed a pattern of upregulated immune-related transcripts (major histocompatibility complex class II, complement system, inflammatory mediators; Table 1), consistent with reports of reactive gliosis and microglial activation in $C n p 1^{K O}$ mice. ${ }^{31}$ Interestingly, components of the complement system can be either deleterious or beneficial. ${ }^{53} \mathrm{~A}$ recent report found upregulation of certain immune-related genes (e.g., c1qc, cd74, Serpina3, tyrobp) was associated with protected cognition in old subjects, ${ }^{54}$ suggesting neuroprotective potential. Here, upregulated immune-related genes in $\mathrm{Cnp}_{1}{ }^{\mathrm{KO}}$ mice show $\sim 40 \%$ overlap with the gene set implicated in that study, suggesting potential mixed deleterious/neuroprotective effects of immune-related gene changes in $C n p 1^{K O}$ mice. Surprisingly, only two neuronal-associated transcripts were found changed (upregulated) in $\mathrm{Cnp} 1^{\mathrm{KO}}$ mice, and both are associated with immune function. Cortistatin, a neuropeptide, has anti-inflammatory and neuroprotective properties in mice $^{55}$ and humans, ${ }^{56,57}$ whereas Serpina3, a serine peptidase inhibitor, is upregulated in response to inflammation in the rodent brain, ${ }^{58,59}$ suggesting a protective role for these genes in $C n p 1^{K O}$ mice.

Whether increased immune- and oligodendrocyte-related transcripts may be an attempt of the system to 'repair' damage and/or protect against further damage owing to the lack of Cnp1-related function, is not known. However, ingenuitybased functional analyses suggest that the two processes are inter-related, a finding consistent with reports in most mental illnesses, ${ }^{60-62}$ and highlighted by the comorbidity of emotion regulation disorders (i.e., anxiety, depression) in patients with multiple sclerosis, an inflammatory demyelinating central nervous system disease. ${ }^{63,64}$ Consequently, Cnp1 could be a critical component of the mechanistic link between oligodendrocytes and immune function underlying psychiatric and other central nervous system disorders. ${ }^{32,65}$

Although the molecular phenotype of the $C n p 1^{K O}$ appears confined to non-neuronal compartments, one of the primary functions of myelinating oligodendrocytes is to support electrical signal conduction along the axon. ${ }^{66}$ The paranode region, where Cnp1 is localized, is critical for maintaining axonal integrity. ${ }^{67,68}$ Cnp1 and other gene products in this region are thought to maintain optimal functioning of axonal mitochondria and it is suggested that perturbations at the paranode could disrupt this fragile metabolic coupling. ${ }^{32}$ Electrophysiological changes in oligodendrocytes can modulate axonal conduction velocity, ${ }^{69}$ and the firing of action potentials in NG2 cells is dependent on axonal synapses, ${ }^{70}$ highlighting the functional connectivity between neurons and oligodendrocytes. ${ }^{71}$ In addition, structural changes in oligodendrocytes, specifically at the paranode region, are suggested to be a potential mechanism for subtle alterations in axonal conduction and associated loss of signal integrity. ${ }^{72,73}$ Accordingly, improper signal conduction in amygdala-related circuitry in $C n p 1^{K O}$ mice (due to paranode disruption) could account for the low encoding of emotionally salient information, and related phenotypic abnormalities. 
Previous studies reported low Cnp1 in MDD and in response to chronic stress ${ }^{13,22}$ (Figure 4). We now demonstrate that disruption of oligodendrocyte function (via Cnp1 ablation) can impact circuits mediating emotionality in mice, leading to a resilient emotionality phenotype. Thus, although these studies indicate that Cnp1 disruption is not likely a causal factor in MDD; the current results suggest that low Cnp1 and/or disruption of a critical axoglial junction may contribute to clinical symptoms of mood disorders in an unexpected and potentially maladaptive way (due to massive molecular changes), and should therefore be further examined in relation to psychiatric illnesses and potential treatments.

\section{Conflict of interest}

The authors declare no conflict of interest.

Acknowledgements. This work was supported by the National Institute of Mental Health MH083410 (NE), MH084060 (ES), MH085111 (ES) and MH077159 (ES). The funding agency had no role in the study design, data collection and analysis, decision to publish and in preparation of the manuscript. The content is solely the responsibility of the authors and does not necessarily represent the official views of the National Institute of Mental Health or the National Institutes of Health. We thank Dr Marianne Seney for giving critical comments on the manuscript.

1. Fields RD. Central role of glia in disease research. Neuron Glia Biol 2010; 6: 91-92.

2. Fields RD. White matter in learning, cognition and psychiatric disorders. Trends Neurosci 2008; 31: 361-370

3. Hercher C, Turecki G, Mechawar N. Through the looking glass: examining neuroanatomical evidence for cellular alterations in major depression. $J$ Psychiatr Res 2009; 43: 947-961.

4. Steiner J, Bielau H, Brisch R, Danos P, Ullrich O, Mawrin C et al. Immunological aspects in the neurobiology of suicide: elevated microglial density in schizophrenia and depression is associated with suicide. J Psychiatr Res 2008; 42: 151-157.

5. Muller N, Schwarz MJ. The immune-mediated alteration of serotonin and glutamate: towards an integrated view of depression. Mol Psychiatry 2007; 12: 988-1000.

6. Miller AH, Maletic V, Raison CL. Inflammation and its discontents: the role of cytokines in the pathophysiology of major depression. Biol Psychiatry 2009; 65: 732-741.

7. Banasr M, Chowdhury GM, Terwilliger R, Newton SS, Duman RS, Behar KL et al. Glial pathology in an animal model of depression: reversal of stress-induced cellular, metabolic and behavioral deficits by the glutamate-modulating drug riluzole. Mol Psychiatry 2010; 15: 501-511.

8. Choudary PV, Molnar M, Evans SJ, Tomita H, Li JZ, Vawter MP et al. Altered cortical glutamatergic and GABAergic signal transmission with glial involvement in depression. Proc Natl Acad Sci USA 2005; 102: 15653-15658.

9. Rajkowska G, Miguel-Hidalgo JJ. Gliogenesis and glial pathology in depression. CNS Neurol Disord Drug Targets 2007; 6: 219-233.

10. Valentine GW, Sanacora G. Targeting glial physiology and glutamate cycling in the treatment of depression. Biochem Pharmacol 2009; 78: 431-439.

11. Hamidi M, Drevets WC, Price JL. Glial reduction in amygdala in major depressive disorder is due to oligodendrocytes. Biol Psychiatry 2004; 55: 563-569.

12. Uranova NA, Vostrikov VM, Orlovskaya DD, Rachmanova VI. Oligodendroglial density in the prefrontal cortex in schizophrenia and mood disorders: a study from the Stanley Neuropathology Consortium. Schizophr Res 2004; 67: 269-275.

13. Sibille $E$, Wang $Y$, Joeyen-Waldorf J, Gaiteri $C$, Surget $A$, Oh $S$ et al. A molecular signature of depression in the amygdala. Am J Psychiatry 2009; 166: 1011-1024.

14. Aston C, Jiang L, Sokolov BP. Transcriptional profiling reveals evidence for signaling and oligodendroglial abnormalities in the temporal cortex from patients with major depressive disorder. Mol Psychiatry 2005; 10: 309-322.

15. Belachew S, Yuan X, Gallo V. Unraveling oligodendrocyte origin and function by cell-specific transgenesis. Dev Neurosci 2001; 23: 287-298.

16. Mallon BS, Shick HE, Kidd GJ, Macklin WB. Proteolipid promoter activity distinguishes two populations of NG2-positive cells throughout neonatal cortical development. J Neurosci 2002; 22: 876-885.

17. Banasr M, Valentine GW, Li XY, Gourley SL, Taylor JR, Duman RS. Chronic unpredictable stress decreases cell proliferation in the cerebral cortex of the adult rat. Biol Psychiatry 2007; 62: 496-504
18. Wennstrom M, Hellsten J, Ekstrand J, Lindgren H, Tingstrom A. Corticosterone-induced inhibition of gliogenesis in rat hippocampus is counteracted by electroconvulsive seizures. Biol Psychiatry 2006; 59: 178-186.

19. Alonso G. Prolonged corticosterone treatment of adult rats inhibits the proliferation of oligodendrocyte progenitors present throughout white and gray matter regions of the brain. Glia 2000; 31: 219-231.

20. Wennstrom M, Hellsten J, Ekdahl CT, Tingstrom A. Electroconvulsive seizures induce proliferation of NG2-expressing glial cells in adult rat hippocampus. Biol Psychiatry 2003; 54: $1015-1024$

21. Wennstrom M, Hellsten J, Tingstrom A. Electroconvulsive seizures induce proliferation of NG2-expressing glial cells in adult rat amygdala. Biol Psychiatry 2004; 55: 464-471

22. Surget A, Wang $Y$, Leman S, Ibarguen-Vargas $Y$, Edgar N, Griebel G et al. Corticolimbic transcriptome changes are state-dependent and region-specific in a rodent model of depression and of antidepressant reversal. Neuropsychopharmacology 2008; 34: 1363-1380.

23. Sequeira A, Mamdani F, Ernst C, Vawter MP, Bunney WE, Lebel V et al. Global brain gene expression analysis links glutamatergic and GABAergic alterations to suicide and major depression. PLoS One 2009; 4: e6585.

24. Peirce TR, Bray NJ, Williams NM, Norton N, Moskvina V, Preece A et al. Convergent evidence for $2^{\prime}, 3^{\prime}$-cyclic nucleotide $3^{\prime}$-phosphodiesterase as a possible susceptibility gene for schizophrenia. Arch Gen Psychiatry 2006; 63: 18-24.

25. Hakak Y, Walker JR, Li C, Wong WH, Davis KL, Buxbaum JD et al. Genome-wide expression analysis reveals dysregulation of myelination-related genes in chronic schizophrenia. Proc Natl Acad Sci USA 2001; 98: 4746-4751.

26. Che R, Tang W, Zhang J, Wei Z, Zhang Z, Huang $\mathrm{K}$ et al. No relationship between $2^{\prime}, 3^{\prime}$-cyclic nucleotide $3^{\prime}$-phosphodiesterase and schizophrenia in the Chinese Han population: an expression study and meta-analysis. BMC Med Genet 2009; 10: 31.

27. Braun PE, Lee J, Gravel M. 2', 3'-cyclic nucleotide $3^{\prime}$-phosphodiesterase: structure, biology, and function. In: Lazzarini RA (ed). Myelin Biology and Disorders 2, vol. 2. Elsevier Academic Press: London, 2004, pp 499-516.

28. Trapp BD, Bernier L, Andrews SB, Colman DR. Cellular and subcellular distribution of $2^{\prime}, 3^{\prime}$-cyclic nucleotide $3^{\prime}$-phosphodiesterase and its mRNA in the rat central nervous system. J Neurochem 1988; 51: 859-868.

29. Gravel M, Robert F, Kottis V, Gallouzi IE, Pelletier J, Braun PE. $2^{\prime}, 3^{\prime}$-Cyclic nucleotide $3^{\prime}$-phosphodiesterase: a novel RNA-binding protein that inhibits protein synthesis. J Neurosci Res 2009; 87: 1069-1079.

30. Edgar JM, McLaughlin M, Werner HB, McCulloch MC, Barrie JA, Brown A et al. Early ultrastructural defects of axons and axon-glia junctions in mice lacking expression of Cnp1. Glia 2009; 57: 1815-1824.

31. Lappe-Siefke C, Goebbels S, Gravel M, Nicksch E, Lee J, Braun PE et al. Disruption of Cnp1 uncouples oligodendroglial functions in axonal support and myelination. Nat Genet 2003; 33: 366-374.

32. Nave KA. Myelination and the trophic support of long axons. Nat Rev Neurosci 2010; 11: 275-283.

33. Guilloux JP, Seney M, Edgar N, Sibille E. Integrated behavioral z-scoring increases the sensitivity and reliability of behavioral phenotyping in mice: relevance to emotionality and sex. J Neurosci Methods 2011; 197: 21-31.

34. Siegle GJ, Steinhauer SR, Thase ME, Stenger VA, Carter CS. Can't shake that feeling: event-related fMRI assessment of sustained amygdala activity in response to emotional information in depressed individuals. Biol Psychiatry 2002; 51: 693-707.

35. Joeyen-Waldorf J, Edgar N, Sibille E. The roles of sex and serotonin transporter levels in age- and stress-related emotionality in mice. Brain Res 2009; 1286: 84-93.

36. Goldman JM, Murr AS, Cooper RL. The rodent estrous cycle: characterization of vaginal cytology and its utility in toxicological studies. Birth Defects Res B Dev Reprod Toxicol 2007; 80: 84-97.

37. Sibille E, Sarnyai Z, Benjamin D, Gal J, Baker H, Toth M. Antisense inhibition of 5-hydroxytryptamine2a receptor induces an antidepressant-like effect in mice. $\mathrm{Mol}$ Pharmacol 1997; 52: 1056-1063.

38. Sierra-Mercado D, Padilla-Coreano N, Quirk GJ. Dissociable roles of prelimbic and infralimbic cortices, ventral hippocampus, and basolateral amygdala in the expression and extinction of conditioned fear. Neuropsychopharmacology 2011; 36: 529-538.

39. Sibille E, Arango V, Joeyen-Waldorf J, Wang Y, Leman S, Surget A et al. Large-scale estimates of cellular origins of mRNAs: enhancing the yield of transcriptome analyses. J Neurosci Methods 2008; 167: 198-206.

40. Rasband MN, Tayler J, Kaga Y, Yang Y, Lappe-Siefke C, Nave KA et al. CNP is required for maintenance of axon-glia interactions at nodes of Ranvier in the CNS. Glia 2005; 50 : 86-90.

41. Conti LH, Jirout M, Breen L, Vanella JJ, Schork NJ, Printz MP. Identification of quantitative trait Loci for anxiety and locomotion phenotypes in rat recombinant inbred strains. Behav Genet 2004; 34: 93-103.

42. Holmes A, Murphy DL, Crawley JN. Abnormal behavioral phenotypes of serotonin transporter knockout mice: parallels with human anxiety and depression. Biol Psychiatry 2003; 54: 953-959.

43. Homberg J, Nijman IJ, Kuijpers S, Cuppen E. Identification of genetic modifiers of behavioral phenotypes in serotonin transporter knockout rats. BMC Genet 2010; 11 : 37. 
44. Feder A, Nestler EJ, Charney DS. Psychobiology and molecular genetics of resilience. Nat Rev Neurosci 2009; 10: 446-457.

45. Southwick SM, Vythilingam M, Charney DS. The psychobiology of depression and resilience to stress: implications for prevention and treatment. Annu Rev Clin Psychol 2005; 1: $255-291$.

46. Kobasa SC. Stressful life events, personality, and health: an inquiry into hardiness. J Pers Soc Psychol 1979; 37: 1-11.

47. Tugade MM, Fredrickson BL. Resilient individuals use positive emotions to bounce back from negative emotional experiences. J Pers Soc Psychol 2004; 86: 320-333.

48. Herry C, Trifilieff $P$, Micheau J, Luthi A, Mons N. Extinction of auditory fear conditioning requires MAPK/ERK activation in the basolateral amygdala. Eur $\mathrm{J}$ Neurosci 2006; 24: 261-269.

49. Sotres-Bayon F, Bush DE, LeDoux JE. Acquisition of fear extinction requires activation of NR2B-containing NMDA receptors in the lateral amygdala. Neuropsychopharmacology 2007; 32: 1929-1940.

50. Jovanovic T, Ressler KJ. How the neurocircuitry and genetics of fear inhibition may inform our understanding of PTSD. Am J Psychiatry 2010; 167: 648-662.

51. Delgado MR, Nearing KI, Ledoux JE, Phelps EA. Neural circuitry underlying the regulation of conditioned fear and its relation to extinction. Neuron 2008; 59: 829-838.

52. Liberzon I, Sripada CS. The functional neuroanatomy of PTSD: a critical review. Prog Brain Res 2008; 167: 151-169.

53. Shen Y, Meri S. Yin and Yang: complement activation and regulation in Alzheimer's disease. Prog Neurobiol 2003; 70: 463-472.

54. Katsel P, Tan W, Haroutunian V. Gain in brain immunity in the oldest-old differentiates cognitively normal from demented individuals. PLoS One 2009; 4: e7642.

55. Gonzalez-Rey E, Chorny A, Robledo G, Delgado M. Cortistatin, a new antiinflammatory peptide with therapeutic effect on lethal endotoxemia. J Exp Med 2006; 203: 563-571.

56. van Hagen PM, Dalm VA, Staal F, Hofland LJ. The role of cortistatin in the human immune system. Mol Cell Endocrinol 2008; 286: 141-147.

57. Carrasco E, Hernandez C, de Torres I, Farres J, Simo R. Lowered cortistatin expression is an early event in the human diabetic retina and is associated with apoptosis and glial activation. Mol Vis 2008; 14: 1496-1502.

58. Tsuda M, Kitagawa K, Imaizumi K, Wanaka A, Tohyama M, Takagi T. Induction of SPI-3 mRNA, encoding a serine protease inhibitor, in gerbil hippocampus after transient forebrain ischemia. Brain Res Mol Brain Res 1996; 35: 314-318.

59. Takamiya A, Takeda M, Yoshida A, Kiyama $H$. Inflammation induces serine protease inhibitor 3 expression in the rat pineal gland. Neuroscience 2002; 113: 387-394.

60. Rao JS, Harry GJ, Rapoport SI, Kim HW. Increased excitotoxicity and neuroinflammatory markers in postmortem frontal cortex from bipolar disorder patients. Mol Psychiatry 2010; 15: 384-392.
61. Ryan MM, Lockstone HE, Huffaker SJ, Wayland MT, Webster MJ, Bahn S. Gene expression analysis of bipolar disorder reveals downregulation of the ubiquitin cycle and alterations in synaptic genes. Mol Psychiatry 2006; 11: 965-978.

62. Shelton RC, Claiborne J, Sidoryk-Wegrzynowicz M, Reddy R, Aschner M, Lewis DA et al. Altered expression of genes involved in inflammation and apoptosis in frontal cortex in major depression. Mol Psychiatry 2010; 16: 751-762.

63. Chwastiak LA, Ehde DM. Psychiatric issues in multiple sclerosis. Psychiatr Clin North Am 2007; 30: 803-817.

64. Hogancamp WE, Rodriguez M, Weinshenker BG. Identification of multiple sclerosisassociated genes. Mayo Clin Proc 1997; 72: 965-976.

65. Konradi C, Sillivan SE, Clay HB. Mitochondria, oligodendrocytes and inflammation in bipolar disorder: evidence from transcriptome studies points to intriguing parallels with multiple sclerosis. Neurobiol Dis 2011 (in press).

66. Poliak S, Peles E. The local differentiation of myelinated axons at nodes of Ranvier. Nat Rev Neurosci 2003; 4: 968-980.

67. Garcia-Fresco GP, Sousa AD, Pillai AM, Moy SS, Crawley JN, Tessarollo L et al. Disruption of axo-glial junctions causes cytoskeletal disorganization and degeneration of Purkinje neuron axons. Proc Natl Acad Sci USA 2006; 103: 5137-5142.

68. Rosenbluth J. Multiple functions of the paranodal junction of myelinated nerve fibers. J Neurosci Res 2009; 87: 3250-3258.

69. Yamazaki Y, Hozumi Y, Kaneko K, Sugihara T, Fujii S, Goto K et al. Modulatory effects of oligodendrocytes on the conduction velocity of action potentials along axons in the alveus of the rat hippocampal CA1 region. Neuron Glia Biol 2007; 3 : 325-334.

70. Karadottir R, Hamilton NB, Bakiri Y, Attwell D. Spiking and nonspiking classes of oligodendrocyte precursor glia in CNS white matter. Nat Neurosci 2008; 11: 450-456.

71. Fields RD. Oligodendrocytes changing the rules: action potentials in glia and oligodendrocytes controlling action potentials. Neuroscientist 2008; 14: 540-543.

72. Yamazaki Y, Hozumi Y, Kaneko K, Fujii S, Goto K, Kato H. Oligodendrocytes: facilitating axonal conduction by more than myelination. Neuroscientist 2010; 16: 11-18.

73. Edgar JM, Nave KA. The role of CNS glia in preserving axon function. Curr Opin Neurobiol 2009; 19: 498-504.

(c) Translational Psychiatry is an open-access journal published by Nature Publishing Group. This work is licensed under the Creative Commons Attribution-Noncommercial-No Derivative Works 3.0 Unported License. To view a copy of this license, visit http://creativecommons.org/licenses/by-nc-nd/3.0/

\section{Supplementary Information accompanies the paper on the Translational Psychiatry website (http://www.nature.com/tp)}

